\title{
Estimación de la integridad uterina en yeguas Pura Raza Chilena y su asociación con edad y número de partos
}

\author{
Estimation Of The Uterine integrity in Chilean PuRebred MaRes ANd ITS ASSOCiation \\ WITH AGE AND FOALING NUMBER
}

Pamela Carolina Morales Muñoz ${ }^{1,2}$, Rodrigo Andrés Castro Sánchez ${ }^{1}$

\section{Resumen}

El presente estudio tuvo por objetivo evaluar la integridad uterina de yeguas Pura Raza Chilena con relación a la edad y número de partos. Se trabajó con 30 yeguas estratificadas según edad (jóvenes: 2-12 años; añosas: $>12$ años) y número de partos ( 0 , $1-2,>2$ partos). Se evaluó la integridad del cérvix y se realizaron biopsias para citología y cultivo microbiológico del endometrio. El 73.3\% de las yeguas presentaron alteraciones histopatológicas sin asociación estadística con edad y número de partos. La citología uterina demostró que el $43.3 \%$ de las yeguas cursaba con endometritis, condición que demostró asociación significativa con edad y número de partos. Escherichia coli fue aislada en 8 de las 10 endometritis bacterianas del estudio. Asimismo, 13 yeguas presentaron anormalidades del cérvix, lo cual se asoció con edad y número de partos. Los resultados indican que la edad y el número de partos son factores que deben ser considerados al evaluar la fertilidad potencial de las yeguas Pura Raza Chilena.

Palabras clave: yeguas; fertilidad; biopsia; citología; microbiología; cérvix

\section{AbSTRACT}

The objective of this study was to evaluate the uterine integrity of Purebred Chilean mares in relation to age and parity number. A total of 30 mares stratified according to age (young: 2-12 years, elder: $>12$ years) and parity $(0,1-2,>2$ parturitions). The integrity of the cervix was evaluated, and biopsies were performed for cytology and microbiological culture of the endometrium. Results showed that $73.3 \%$ of the mares had histopathological alterations without statistical association with age and parity. The uterine cytology

\footnotetext{
${ }^{1}$ Facultad de Recursos Naturales y Medicina Veterinaria, Universidad Santo Tomás, Talca, Chile

${ }^{2}$ E-mail:pmoralesm@santotomas.cl
} 
showed that $43.3 \%$ of the mares had endometritis, a condition that showed significant association with age and parity. Escherichia coli was isolated in 8 of the 10 cases of bacterial endometritis of the study. Also, 13 mares presented abnormalities of the cervix, which was associated with age and parity. The results indicated that the age and parity number are factors that should be considered when evaluating the potential fertility of Purebred Chilean Mares.

Key words: mares; fertility; biopsy; cytology; microbiology; cervix

\section{INTRODUCCIÓN}

El caballo Pura Raza Chileno posee los registros genealógicos más antiguos de Sudamérica y es utilizado fundamentalmente en el rodeo, disciplina considerada deporte nacional en Chile. En las últimas décadas ha despertado el interés de otros países debido a sus características morfofuncionales, rusticidad y adaptación a diversos trabajos, lo cual ha permitido su exportación para ser utilizado en el mejoramiento genético de otras razas criollas (Pérez y Huber, 2004). A pesar de la importancia económica y sociocultural que reviste la producción de esta raza en particular, existe escasa información científica que describa sus variables reproductivas, generando que la estimación de su fertilidad se realice en base a la extrapolación de los parámetros descritos para las razas más estudiadas.

Considerando que la yegua se ha transformado en una inversión para el propietario, la estimación de la fertilidad potencial de los ejemplares en un plantel o haras es de gran importancia (LeBlanc et al., 2003; Rivera, 2003; Katila, 2016).

La edad y el número de partos están inversamente relacionados con la fertilidad en yeguas Fina Sangre de Carrera debido a la pérdida de la integridad anatómica e inmunitaria del tracto reproductivo en ejemplares añosos y multíparos, donde se puede observar una mayor frecuencia de alteraciones histológicas del útero (fibrosis periglan- dular, pleomorfismo endometrial, infiltración de células inflamatorias, nidos glandulares y endometriosis) que predisponen a la pérdida embrionaria temprana, aborto o dificultad para preñar (Hurtgen, 2006; Causey, 2007; Kilgenstein et al., 2015; Claes et al., 2017). En las yeguas Pura Raza Chilena no ha sido descrita esta asociación; sin embargo, su evaluación es de interés, dado que, debido a las particularidades de su reproducción y crianza, inician tardíamente su actividad deportiva, trayendo como consecuencia que la población de yeguas añosas y multíparas sea cada vez más representativa dentro de los planteles.

La integridad uterina está directamente relacionada con la fertilidad de modo que su estimación es de vital importancia durante la evaluación reproductiva. Dentro de los procedimientos diagnósticos más empleados se encuentran la evaluación de la integridad cervical, citología uterina, biopsia endometrial y cultivo bacteriano de útero. Cada uno posee valor diagnóstico, pero su utilidad aumenta cuando son utilizados en conjunto (Waelchli, 1990; Doig y Waelchi, 1993; Yamashiro, 2002; Katila, 2016).

La endometritis es considerada la principal causa de infertilidad en la yegua, generando irregularidad de los ciclos reproductivos, pérdida embrionaria temprana y abortos (Causey 2007; Ricketts y Troedsson 2007; Katila, 2016). Aunque la endometritis puede ser aséptica, generalmente es de origen bacteriano asociada a la vía de ingreso ascendente; es decir, microorganismos habitua- 
les del periné que ingresan al tracto reproductivo producto de una mala conformación anatómica a nivel vulvar, vestibular y principalmente del cérvix, sumado a una alteración inmunitaria uterina (Hurtgen, 2006; Causey, 2007). La flora patógena normalmente encontrada en endometritis bacterianas está representada por Streptococcus B hemolítico, Pseudomonas aeroginosa, Klebsiella pneumoniae, Escherichia coli, Staphylococcus coagulasa negativo y Proteus spp (Overbeck et al. 2011). Comprender la fisiopatología de esta enfermedad e identificar los factores predisponentes es fundamental para su monitoreo, control y diagnóstico (Causey, 2007; LeBlanc y Causey, 2009; Katila, 2016).

El presente estudio tuvo por objetivo obtener información sobre la integridad uterina de un grupo de yeguas Pura Raza Chilena, asociando las variables uterinas a la edad y número de partos, para una mejor comprensión de las variaciones de la fertilidad potencial en los sistemas productivos de esta raza.

\section{Materiales y Métodos}

\section{Animales}

Mediante la fórmula de tamaño muestral para poblaciones finitas (Milton, 2001), aplicada a un total de 60 yeguas disponibles y considerando un $95 \%$ de confianza, $8 \%$ de precisión y $10 \%$ de prevalencia de endometritis (McKinnon y Voss, 1993), fueron utilizadas 30 yeguas Pura Raza Chilena, provenientes de siete planteles de la Región del Maule (VII Región), Chile. Se consideraron los siguientes criterios de exclusión: yeguas gestantes, yeguas clínicamente enfermas o con anormalidades detectables mediante examen ginecológico, yeguas con tratamientos antinflamatorios o antibacterianos en curso, yeguas con monta o inseminación artificial en el ciclo estral vigente, yeguas den- tro de los 10 días del parto y yeguas menores de 2 y mayores de 18 años.

Cada yegua fue sometida a examen clínico reproductivo completo, caracterizando el estado del ciclo reproductivo que cursaban mediante la realización de ecografía reproductiva vía transrectal (Ecógrafo Welld WED-3000V, transductor lineal de $5 \mathrm{MHz}$ ). Para cada ejemplar se registró la edad, número de partos y estado del ciclo estral.

\section{Estudio Anatómico del Cérvix}

Se evaluó la integridad del cérvix mediante vaginoscopía (espéculo desechable Minitube ${ }^{\circledR} 17210 / 0000$ ) y se consideró la presencia/ausencia de laceraciones, la presencia/ausencia de adherencias y la presencia/ ausencia de traumatismos o inflamación. En el caso de observar una o más de las alteraciones mencionadas, el cérvix fue considerado como anormal; caso contrario fue considerado como normal.

\section{Estudio Bacteriológico del Endometrio}

Utilizando tórulas estériles (Minitube ${ }^{\circledR}$ 17214/2951), se obtuvieron muestras de endometrio que fueron procesados antes de 24 horas. Las muestras fueron sembradas en tres medios de cultivo: agar sangre, agar McConkey y agar salino Manitol, y mantenidas por 48 horas a $37^{\circ} \mathrm{C}$. Se consideró contaminación de la muestra cuando crecieron más de tres tipos bacterianos y se consideró infección uterina cuando el cultivo bacteriano resultó ser un monocultivo ( $90 \%$ de las colonias en crecimiento correspondiendo a un solo tipo bacteriano) o ante el aislamiento de Streptococcus B hemolítico, Pseudomonas aeroginosa, Klebsiella pneumoniae, Escherichia coli, Staphylococcus coagulasa negativo o Proteus spp (Overbeck et al., 2011). Se consideró sin desarrollo cuando no hubo crecimiento bacteriano pasadas las 72 horas de cultivo. 


\section{Estudio Citológico del Endometrio}

Se obtuvieron muestras endometriales utilizando el mismo tipo de tórulas anteriormente descritas. Las muestras fueron inmediatamente extendidas de manera uniforme sobre tres portaobjetos de vidrio, rociadas con fijador celular en spray (Cito-fix ${ }^{\circledR}$, Laboratorios Linsan) y secadas a temperatura ambiente durante 10 minutos. Luego fueron teñidas con un kit de tinción rápida (Hemacolor ${ }^{\circledR}$, Laboratorio Merck) según las indicaciones del fabricante.

Las láminas fueron visualizadas bajo un microscopio de luz convencional (Axiostar Plus, Zeiss, Carl Zeiss) con objetivos de 10X y $40 X$. Se contaron 200 células por portaobjeto y se determinó el número de células endometriales y polimorfos nucleares neutrófilos (PMN), a fin de calcular el porcentaje de PMN. Se consideró el siguiente criterio de clasificación: endometrio normal $<5 \%$ PMN; endometritis $\geq 5 \%$ PMN (Nielsen et al., 2010).

\section{Estudio Histopatológico del Endometrio}

Se obtuvieron muestras de endometrio mediante biopsia tomada con pinza de biopsia uterina (Krusse N. ${ }^{\circ} 141965$ ). El tejido fue inmediatamente fijado en formalina al $10 \% \mathrm{y}$ luego se realizó un procedimiento histológico de rutina. Se obtuvieron cortes de $5 \mu \mathrm{m}$ y se realizó tinción corriente con HemotoxilinaEosina. Las muestras fueron evaluadas bajo microscopio óptico (Axiostar Plus, Zeiss, Carl Zeiss) con objetivos de 10X y 40X.

Se evaluó el grado de fibrosis periglandular, pleomorfismo de células epiteliales, infiltración de células inflamatorias y conformación de nidos glandulares. Las muestras fueron clasificadas a doble ciego según la escala descrita por Kenney y Doig (1986), la cual reconoce cuatro grupos en escala ascendente según número e intensidad de las alteraciones (I, IIA, IIB y III) (Schlafer, 2007). Ver Cuadro 1. Los resultados en este estudio fueron agrupados en dos categorías: útero normal: I y IIA; útero patológico: IIB y III.

\section{Análisis Estadístico}

Los resultados fueron agrupados según las variables cervicales (normal; anormal), citología endometrial (sin endometritis; endometritis), bacteriológicas (sin desarrollo bacteriano; infección) e histopatológicas (útero normal; útero patológico). Se conformaron dos tablas de frecuencias según los criterios de edad y número de partos: edad (jóvenes: 2 a 12 años; añosas: más de 12 años) y número de partos $(0 ; 1-2 ;>2$ partos $)$, que sirvieron para estructurar las tablas de contingencia en el análisis estadístico.

Para determinar asociación de las variables edad y número de partos con las variables cervicales, citológicas, bacteriológicas e histopatológicas, se realizó una prueba de independencia utilizando el estadígrafo $\mathrm{Chi}$ cuadrado. Además, se calculó el riesgo relativo (Odds ratio) de la condición predisponente. Los cálculos fueron realizados utilizando el software estadístico Stata $8.0^{\circledR}$ para Windows (College Station, TX: StataCorp LP) considerando un $\mathrm{p}<0.05$ como significativo.

\section{Resultados}

La edad de las yeguas fue de $10.6 \pm 5.1$ años (promedio \pm desviación estándar) y el número de partos fue de $1.7 \pm 2.3$. El 46.6\% de las yeguas se encontraba en estro, mientras que el $53.4 \%$ restante estaba en diestro. El grupo de yeguas añosas $(n=12)$ tenía 15.9 \pm 1.3 años y el grupo de yeguas jóvenes $(\mathrm{n}=18)$ tenía $7.2 \pm 2.9$ años. Así mismo, el grupo de yeguas con 0 partos $(n=13)$ representó el $43.3 \%$ del grupo en estudio, las yeguas con 1-2 partos $(n=7)$ representaron el $23.3 \%$ y el grupo de yeguas con más de 2 partos $(\mathrm{n}=10)$ representó el $33.4 \%$. El 84.6\% de las yeguas añosas presentan al menos un 
Cuadro 1. Alteraciones histopatológicas uterinas según categorización de Kenney y Doig (1986)

\begin{tabular}{|c|c|c|c|}
\hline Grado & Alteraciones histopatológicas & Lesiones & $\begin{array}{c}\text { Índice de } \\
\text { preñez } \\
(\%)\end{array}$ \\
\hline I & - Sin cambios patológicos & Ausente & $80-90$ \\
\hline IIA & $\begin{array}{l}\text { - Infiltración inflamatoria difusa en estrato compacto } \\
\text { - Focos inflamatorios dispersos y frecuente en estrato } \\
\text { esponjoso } \\
\text { - Compromiso de ramas glandulares } \\
\text { - Nidos fibróticos cada cuatro campos ópticos } \\
\text { - Atrofia parcial de endometrio }\end{array}$ & Leve & $50-80$ \\
\hline IIB & $\begin{array}{l}\text { - Focos inflamatorios diseminados en epitelio luminal, } \\
\text { estrato compacto y esponjoso } \\
\text { - Fibrosis severa } \\
\text { - Un nido fibrótico por campo } \\
\text { - Dilatación glandular quística } \\
\text { - Atrofia diseminada }\end{array}$ & Moderado & $10-50$ \\
\hline III & $\begin{array}{l}\text { - Fibrosis periglandular generalizada } \\
\text { - Cinco nidos cada cuatro campos ópticos } \\
\text { - Inflamación severa } \\
\text { - Endometrio hipoplásico }\end{array}$ & Severo & $<10$ \\
\hline
\end{tabular}

parto en su historial reproductivo, y con un promedio de 4.2 partos.

En el estudio citológico del endometrio, $13 / 30(43.3 \%)$ presentaron endometritis, siendo $83.3 \%$ de yeguas añosas y $16.7 \%$ de yeguas jóvenes $(\mathrm{p}=0.0001)$. En el caso de los grupos según número de partos, el $80 \%$ de las yeguas con más de 2 partos presentaron endometritis $(\mathrm{p}=0.016)$ en comparación con el $28.6 \%$ en el grupo de yeguas con 1-2 partos y el $23.1 \%$ en el grupo de yeguas con 0 partos (Cuadro 2, Figura 1a). Las yeguas añosas poseen 25 veces más riesgo de presentar endometritis (Odds ratio 25; I.C. 95\% $=2.75-301.39$ ).

Catorce yeguas presentaron desarrollo bacteriano uterino (endometritis bacteriana), condición observada en el $66.7 \%$ de las yeguas añosas y en el 33.3\% de las yeguas jó- venes. Así también, la endometritis bacteriana estuvo presente en el $23.1 \%$ de las yeguas nulíparas, $42.9 \%$ de las yeguas de 1-2 partos y en el $80 \%$ de las yeguas con más de dos partos (Cuadro 2). Sin embargo, no hubo asociación estadística entre la presentación de endometritis bacteriana y la variable edad $(\mathrm{p}=0.631)$ y número de partos $(\mathrm{p}=0.116)$.

De las 13 yeguas con citología concordante con endometritis, se observaron 10 con crecimiento bacteriano en el endometrio. $E$. coli fue aislada en 8 de las 10 endometritis bacterianas, representando al patógeno más frecuente, aislándose Klebsiella pneumoniae y Staphyloccocus coagulasa (-) en los otros dos casos. Cuatro yeguas presentaron crecimiento bacteriano uterino sin poseer una citología concordante con endometritis, en estos casos el agente aislado fue Streptococcus B hemolítico. 
Cuadro 2. Hallazgos anatómicos, bacteriológicos, citológicos e histopatológicos del cérvix y útero de yeguas Pura Raza Chilena, según la edad y número de parto

\begin{tabular}{lcccccccc}
\hline & $\begin{array}{c}\text { Estudio } \\
\text { anatómico del } \\
\text { cérvix }\end{array}$ & $\begin{array}{c}\text { Estudio } \\
\text { bacteriológico } \\
\text { del endometrio }\end{array}$ & $\begin{array}{c}\text { Estudio } \\
\text { citológico del } \\
\text { endometrio }\end{array}$ & $\begin{array}{c}\text { Estudio } \\
\text { histopatológico } \\
\text { del endometrio }\end{array}$ \\
\hline & Anormal & Con desarrollo & \multicolumn{2}{c}{$\begin{array}{c}\text { Con } \\
\text { endometritis }\end{array}$} & \multicolumn{2}{c}{ Patológico } \\
\cline { 2 - 10 } & $\mathrm{n}$ & $\%$ & $\mathrm{n}$ & $\%$ & $\mathrm{n}$ & $\%$ & $\mathrm{n}$ & $\%$ \\
\hline Jóvenes $(\mathrm{n}=18)$ & 5 & 27.8 & 6 & 33.3 & 3 & 16.7 & 12 & 66.67 \\
Añosas $(\mathrm{n}=12)$ & 8 & 66.7 & 8 & 66.7 & 10 & 83.3 & 10 & 83.33 \\
0 partos $(\mathrm{n}=13)$ & 4 & 30.8 & 3 & 23.1 & 3 & 23.1 & 9 & 69.23 \\
1-2 partos $(\mathrm{n}=7)$ & 1 & 14.3 & 3 & 42.9 & 2 & 28.6 & 5 & 71.43 \\
$>2$ partos $(\mathrm{n}=10)$ & 8 & 80.0 & 8 & 80.0 & 8 & 80.0 & 8 & 80.00 \\
\hline
\end{tabular}

En el estudio anatómico del cérvix uterino, 13 ejemplares $(43.3 \%)$ presentaron alguna de las alteraciones descritas para la condición anormal, determinándose que existe asociación con el grupo de mayor edad $(\mathrm{p}=0.035)$, ya que el $66.7 \%$ de yeguas añosas presentó cérvix alterado en comparación con el $27.8 \%$ de las yeguas jóvenes. También se determinó una asociación estadística entre la alteración del cérvix y el número de partos ( $\mathrm{p}=0.013$ ), donde el $80 \%$ de las yeguas con más de 2 partos presentaron cérvix anormal, en comparación con el 14.3 y $30.8 \%$ en yeguas con 1-2 y 0 partos, respectivamente (Cuadro 2). Además, se encontró una alta asociación entre la presentación de cérvix anormal y la condición de infección uterina $(\mathrm{p}=0.004)$, donde las yeguas con anormalidades cervicales presentan 10.83 veces más riesgo de generar crecimiento bacteriano intrauterino (Odds ratio 10.83; I.C. $95 \%=1.55$ $-86.26)$.

En el estudio histopatológico del endometrio, la mitad de las yeguas en estudio se clasificó en la categoría IIB, mientras que ningún ejemplar calificó para la categoría I. El 73.3\% de las yeguas fue considerado en la categoría de úteros patológicos (Categoría IIB y III) (Figura 1 b,c). No hubo asociaciones estadísticas para las variables edad y número de partos con la variable categorización histopatológica del útero ( $\mathrm{p}=0.312$ y $\mathrm{p}=0.839$, respectivamente); $\sin$ embargo, el mayor número de hallazgos histopatológicos severos (Categoría III) se presentó en los grupos de mayor edad (83.3\% en yeguas añosas vs. $66.6 \%$ en yeguas jóvenes) y en el grupo de yeguas con más de dos partos (80\%) (Cuadro 2; Figura 1d).

\section{Discusión}

En términos generales para todas las razas equinas, las yeguas adquieren valor genético, deportivo y económico, una vez que han cumplido con una reconocida campaña deportiva o hayan tenido crías de similares características. Así, Rivera (2003) y Cadario (2011) afirman que la población geriátrica equina ha aumentado considerablemente, lo que complica su potencial reproductivo. $\mathrm{La}$ literatura científica indica que en este grupo etario confluye una serie de trastornos morfológicos y funcionales (alteraciones inmunológicas, metabólicas, endocrinas y anatómicas), que repercuten negativamente en el potencial reproductivo de las yeguas y que se deben tener en consideración (LeBlanc y Causey, 2009; Cadario, 2011; Losinno, 2011; 


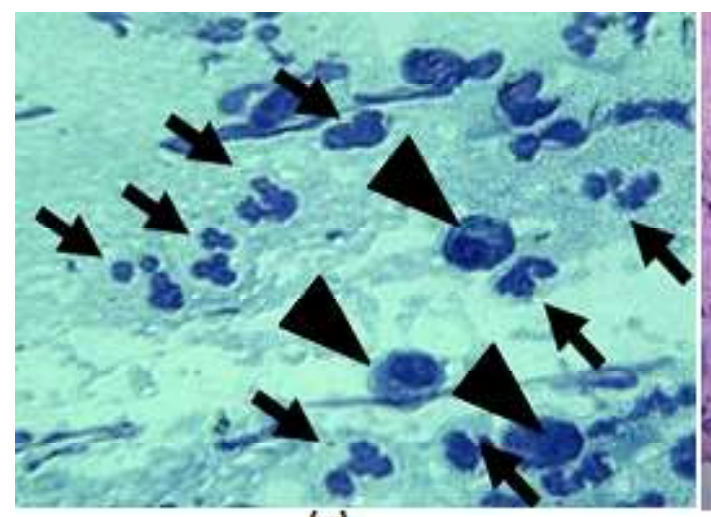

(a)

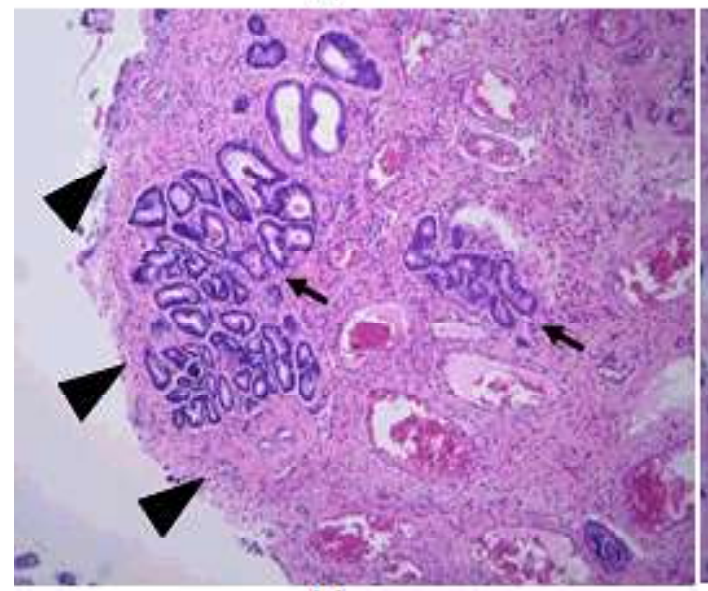

(c)

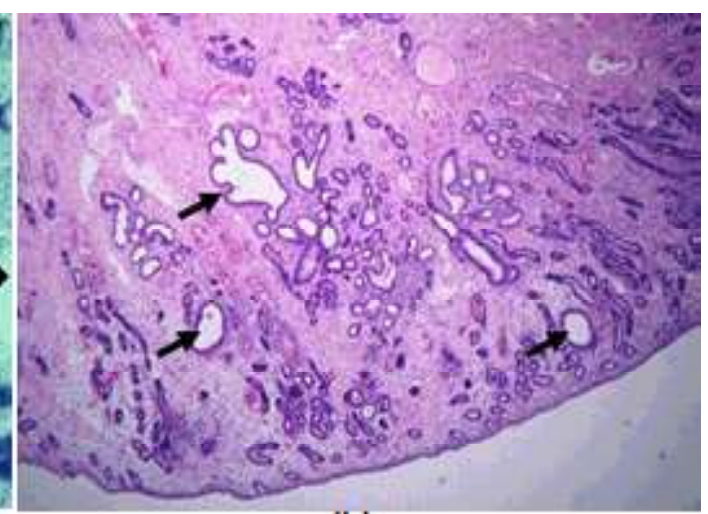

(b)

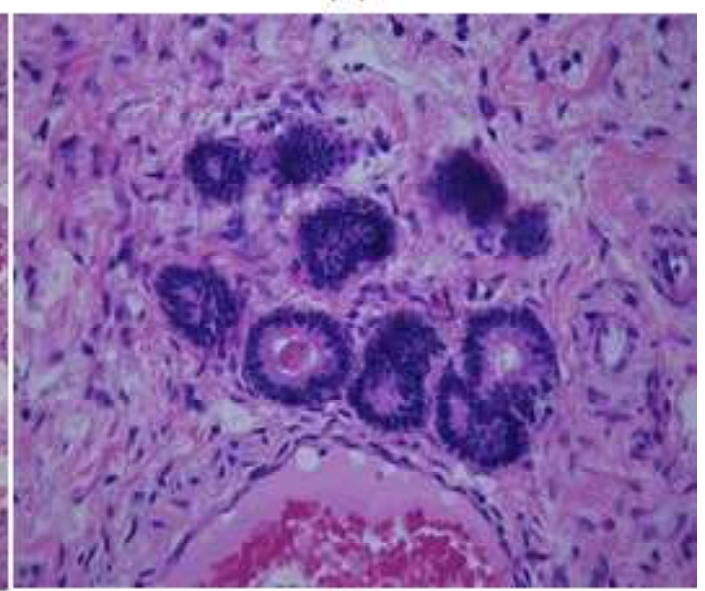

(d)

Figura 1. a) Citología uterina de una yegua añosa ( 15 años) y multípara ( 4 partos). Se observa la presencia de células endometriales (puntas de flechas) y una abundante cantidad de PMN (flechas). 40X. Colorante Hemacolor (Merck ${ }^{\circledR}$ ) (b) Biopsia endometrial de una yegua añosa (17 años) y multípara (4 partos) clasificada en categoría IIB, según escala de Kenney y Doig (1986). Se observa la presencia de glándulas quísticas (flechas) y una distribución heterogénea de las glándulas endometriales. 10 X. Tinción HE. (c) Biopsia endometrial de una yegua añosa (15 años) y multípara (5 partos) clasificada en categoría III, según Kenney y Doig (1986). Se observa la presencia de nidos glandulares (flechas) y ausencia de epitelio endometrial (puntas de flechas). 10X. Tinción HE. (d) Biopsia endometrial de una yegua añosa (17 años) y multípara (4 partos) clasificada en categoría III, según Kenney y Doig (1986). Se observa un nido glandular rodeado de matriz extracelular colagenosa y fibroblastos. 40X. Tinción HE

Marinone et al., 2017). En el caso de los ejemplares Pura Raza Chilena, esta condición se ve potenciada debido a que las yeguas comienzan tardíamente su actividad deportiva, de allí que el inicio de su actividad reproductiva también se retarda, permitiendo que coincida con una etapa de baja fertilidad.
Los hallazgos histopatológicos del útero concuerdan con las descritas por Schlafer (2007) y Castañeira (2009) para otras razas de equinos; es decir, pleomorfismo de células epiteliales, fibrosis periglandular, glándulas quísticas, nidos glandulares, lagunas linfáticas e infiltración de células inflamatorias. 
Doig et al. (1981), Schlafer (2007) y Woodward et al. (2012) describen que el grado de fibrosis endometrial es mayor a medida que el promedio de edad de las yeguas aumenta. Esta situación se vio reflejada en este estudio, donde a pesar de no encontrar una significancia estadística en la asociación de las variables, se observó que las lesiones histopatológicas severas (categoría III) fueron observadas en mayor porcentaje en las yeguas añosas y con más de dos partos. Además, el $73.3 \%$ de las yeguas presentó úteros categorizados histológicamente con lesiones moderadas o severas (IIB y III, respectivamente), por lo cual, a pesar de ser utilizadas como reproductoras, son consideradas subfértiles, evidenciando que la selección de los ejemplares reproductores prioriza variables deportivas por sobre las variables reproductivas, hecho que dificulta el éxito reproductivo.

En el presente estudio fue posible determinar asociación entre edad y endometritis, generando que las yeguas añosas tengan un factor de riesgo asociado a presentar endometritis 25 veces más que en yeguas jóvenes; resultado que concuerda con Pardo (2010) en yeguas Fina Sangre de Carrera, quién encontró que el $71 \%$ de yeguas de edad avanzada presentaron endometritis. Según Hurtgen (2006), Adams et al. (2008), LeBlanc (2008), Pardo (2010) y Brinsko et al. (2011), uno de los factores principales y más críticos que predisponen a que las yeguas añosas presenten endometritis, además de las causas metabólicas, es la pérdida progresiva de la tonicidad uterina y la disminución en la respuesta de la inmunidad celular, representada por una menor tasa de división de linfocitos $\mathrm{T}$ y producción de citoquinas, lo cual predispone al acúmulo de líquido seminal posmonta y detritus posparto.

En el presente estudio se evidenció que yeguas con más de dos partos presentaron el mayor porcentaje de endometritis. Hurtgen (2006) indica que la posición ventral que adopta el útero luego de múltiples gestaciones contribuye a la acumulación de fluidos durante el celo o el posparto temprano, debido a la dificultad de expulsarlos al exterior, por efectos de la gravedad. Esto, además de predisponer a endometritis crónica, genera una tensión o distensión en las estructuras anatómicas caudales como el cérvix y los ligamentos de sostén.

Según LeBlanc y Causey (2009), las yeguas con menor número de partos poseen una morfología cervical libre de alteraciones, $\mathrm{y}$ aquellas con mayor número de partos sufren defectos en las barreras físicas del cérvix como laceraciones y adherencias, situación que pudiera predisponer el ingreso de bacterias al útero. En este estudio la observación de cérvix anormal se relacionó con edad avanzada, condición multípara y con infección del útero. Rivera (2003), Hurtgen (2006), Causey (2007), Ricketts y Troedsson (2007) también manifiestan la importancia que se le atribuye a la integridad de las estructuras anatómicas del tracto reproductivo, como activos participantes de las barreras inmunitarias, asegurando un ambiente uterino libre de contaminantes, evitando fundamentalmente el ingreso de bacterias por la vía ascendente.

En el presente trabajo, E. coli mostró la mayor frecuencia de aislamiento en útero, concordante con el estudio de Causey (2007), quien indica a esta bacteria como el principal microorganismo a nivel vaginal y uterino, $y$ que puede ingresar al útero y tornarse patógeno cuando el ambiente e inmunidad uterina se ven alterados. Gallardo de López et al. (1982) y Overbeck et al. (2011) mencionan que $E$. coli es una bacteria invasora oportunista que forma parte de la flora normal del periné, labios vulvares, vestíbulo posterior y fosa clitórica de la yegua.

Por lo descrito anteriormente, la evaluación morfológica del tracto reproductivo de las yeguas es de fundamental importancia durante la realización del examen ginecológico, así como también la obtención de muestras uterinas para análisis histopatológico, citológicos y bacteriológicos; 
sobre todo en aquellos ejemplares de edad avanzada y con más de dos partos en su historial reproductivo. Los resultados de este estudio corresponden a un aporte directo y específico para yeguas Pura Raza Chilena y pueden ser considerados como parámetro de referencia para tomar decisiones reproductivas dentro del plantel.

\section{Conclusiones}

- No se encontró asociación estadísticamente significativa entre edad, número de partos y condición histopatológica uterina en yeguas Pura Raza Chilena.

- Existe una relación entre edad, número de partos y presencia de endometritis diagnosticada por citología en yeguas Pura Raza Chilena.

- Existe una asociación entre edad, número de partos, y endometritis con la presencia de cérvix alterado en yeguas Pura Raza Chilena.

- Escherichia coli mostró ser el patógeno de mayor frecuencia de aislamiento en útero de yeguas Pura Raza Chilena.

\section{Literatura Citada}

1. Adams A, Breathnach C, Ketapalli M, Kohler K, Horohov D. 2008. Advanced age in horse effects divisional history of $\mathrm{T}$ cells and inflammatory cytokine production. Mech Ageing Dev 129: 656664. doi: 10.1016/j.mad.2008.09.004

2. Brinsko S, Blanchard T, Varner D, Schumacher J, Love C, Hinrichs K, Hartman D. 2011. Endometritis, manual of equine reproduction. $3^{\text {rd }}$ ed. USA: Elsevier. $336 \mathrm{p}$.

3. Cadario M. 2011. Enfermedades metabólicas e infertilidad en la yegua. En: I Simposio Latinoamericano de Reproducción Animal. Viña del Mar, Chile.

4. Castañeira C. 2009. Lectura e interpretación de la biopsia endometrial en la yegua. En: $1^{\circ}$ Congreso Argentino de
Reproducción Equina. Buenos Aires, Argentina.

5. Causey R. 2007. Uterine therapy for mares with bacterial infections. In: Samper J, Pycock J, McKinnon A (eds). Current therapy in equine reproduction. USA: Saunders. p 105-115.

6. Claes A, Ball B, Scoggin K, Roser J, Woodward E, Davolli G, Squires E, Troedsson M. 2017. The influence of age, antral follicle count and diestrous ovulations on estrous cycle characteristics of mares. Theriogenology 97: 34-40. doi: 10.1016/j.theriogenology.2017.04.019

7. Doig P, McKnight, Miller R. 1981. The use of endometrial biopsy in the infertile mare. Can Vet J 22: 72-76.

8. Doig P, Waelchi R. 1993. Reproductive examination in the mare. In: McKinnon A, Voss J (eds). Equine reproduction. USA: Lea \& Febiger. p 225-234.

9. Gallardo de López A, Polanco J, Yuraima P, De Aponte F. 1982. Flora bacteriana aérobica del útero de yeguas infértiles. Vet Trop 7: 3-17.

10. Hurtgen J. 2006. Pathogenesis and treatment of endometritis in the mare: a review. Theriogenology 66: 560-566. doi: 10.1016/j.theriogenology.2006.04.006

11. Katila T. 2016. Evaluation of diagnostic methods in equine endometritis. Reprod Biol 16: 189-196. doi: 10.1016/ j.repbio.2016.06.002

12. Kenney R, Doig P. 1986. Equine endometrial biopsy. In: Morrow D (ed). Current therapy in theriogenology. $2^{\text {nd }} e d$. USA: Lea and Febiger. p 723-729.

13. Kilgenstein H, Schöniger S, Schoon D, Schoon H. 2015. Microscopic examination of endometrial biopsies of retired sports mares: an explanation for the clinically observed subfertility? Res Vet Sci 99: 171-179. doi: 10.1016/ j.rvsc. 2015.01.005

14. LeBlanc M. 2008. When to refer an infertile mare to a theriogenologist. Theriogenology 70: 421-429. doi: 10.1016/j.theriogenology.2008.04.021 
15. LeBlanc M, Causey R. 2009. Clinical and subclinical endometritis in the mare: both threats to fertility. Reprod Dom Anim 44: 10-22. doi: 10.1111/j.14390531.2009.01485.x

16. LeBlanc M, Lopate C, Knottenbelt D, Pascoe R. 2003. The mare. In: Knottenbelt D (ed). Equine stud farm medicine and surgery. USA: Saunders. p 113-211.

17. Losinno L. 2011. Aspectos biológicos y clínicos del envejecimiento reproductivo en la yegua. En: I Simposio Latinoamericano de Reproducción Animal. Viña del Mar, Chile.

18. McKinnon A, Voss J. 1993. Equine reproduction. Philadelphia, USA: Lea \& Febiger. $720 \mathrm{p}$.

19. Marinone A, Mucci $N$, Kaiser G, Losinno L, Armendano J, Rodriguez E, Mutto A, et al. 2017. Reproductive characteristics in old and young subfertile mares: are they different? J Equine Vet Sci 55: 90-96. doi: 10.1016/j.jevs.2017.02.012

20. Milton S. 2001. Estadística para biología y ciencias de la salud. $3^{\text {rd }}$ ed. Madrid: McGraw-Hill Interamericana. 1137 p.

21. Nielsen J, Troedsson M, Pedersen MR, Bojesen A, Lehn-Jensen H. Zent W. 2010. Diagnosis of endometritis in the mare based on bacteriological and cytological examinations of the endometrium: comparison of results obtained by swabs and biopsies. J Equine Vet Sci 30: 27-30. doi: 10.1016/ j.jevs.2009.11.006

22. Overbeck W, Witte T, Heuwieser W. 2011. Comparison of three diagnostic methods to identify subclinical endometritis in mares. Theriogenology 75: 1311-1318. doi: 10.1016/ j.theriogenology.2010.12.002
23. Pardo J. 2010. Relación entre la citología uterina y la preñez en yeguas fina sangre de carrera. Tesis de Médico Veterinario. Valdivia: Univ. Austral de Chile. 55 p.

24. Pérez V, Huber A. 2004. El gran libro del caballo chileno: historia y tradición de un país. Santiago, Chile: Creación y desarrollo editorial. $159 \mathrm{p}$.

25. Ricketts S, Troedsson M. 2007. Female reproductive problems: diagnosis and management. In: Samper J, Pycock J, McKinnon A (eds). Current therapy in equine reproduction. USA: Saunders. $p$ 53-69.

26. Rivera G. 2003. Caracterización histopatológica del endometrio de yeguas con antecedentes clínico-reproductivos de subfertilidad. Tesis de Médico Veterinario. Valdivia, Chile: Univ. Austral de Chile. $60 \mathrm{p}$.

27. Schlafer D. 2007. Equine endometrial biopsy: enhancement of clinical value by more extensive histopathology and application of new diagnostic techniques? Theriogenology 68: 413-422. doi: 10.1016/j.theriogenology.-2007.04.040

28. Waelchli R. 1990. Endometrial biopsy in mares under nonuniform breeding management conditions: prognostic value and relationship with age. Can Vet J 31: 379-384.

29. Woodward E, Christoffersen M, Campos J, Squires E, Troedsson M. 2012. Susceptibility to persistent breedinginduced endometritis in the mare: Relationship to endometrial biopsy score and age, and variations between seasons. Theriogenology 78: 495-501. doi: 10.1016/j.theriogenology.2012.02.028

30. Yamashiro S. 2002. Comparative veterinary histology with clinical correlates. Can Vet J 43: 104. 